\title{
Altimeter Estimation of Sea Surface Wind Stress for Light to Moderate Winds
}

\author{
DOUGLAS VANDEMARK \\ NASA/Goddard Space Flight Center, Wallops Island, Virginia \\ JAMES B. EDSON \\ Woods Hole Oceanographic Institution, Woods Hole, Massachusetts \\ BERTRAND CHAPRON \\ Institut Français de Recherche pour l'Exploitation de la Mer, Plouzane, France \\ 3 May 1996 and 10 September 1996
}

\begin{abstract}
Aircraft altimeter and in situ measurements are used to examine relationships between altimeter backscatter and the magnitude of near-surface wind and friction velocities. Comparison of altimeter radar cross section with wind speed is made through the modified Chelton-Wentz algorithm. Improved agreement is found after correcting $10-\mathrm{m}$ winds for both surface current and atmospheric stability. An altimeter friction velocity algorithm is derived based on the wind speed model and an open-ocean drag coefficient. Close agreement between altimeter- and in situ-derived friction velocities is found. For this dataset, quality of the altimeter inversion to surface friction velocity is comparable to that for adjusted winds and clearly better than the inversion to true 10-m wind speed.
\end{abstract}

\section{Introduction}

Relationships between ocean wind speed, wind stress, and microwave remote sensing are both elementary and complicated. Because of the relative ease and availability of wind speed measurements, ocean wind speed algorithms for the scatterometer, altimeter, and radiometer have been the first developed. Wind models for these three sensors have been demonstrated with uncertainty of order $2 \mathrm{~m} \mathrm{~s}^{-1}$ (Stoffelen and Anderson 1993; Witter and Chelton 1991; Wentz 1992). The physics behind these semiempirical wind algorithms is quite different for each sensor. For each case, it is clear they cannot directly map their respective measurement to the $10-\mathrm{m}$ wind speed. For radar scatterometers, known contamination of wind speed inversion can come from nonwind geophysical effects such as atmospheric stratification, current or SST fronts, surfactant, and sea state. To account for these influences, some have suggested relating scatterometer measurements directly to surface friction velocity $u_{*}$, a measure of wind stress that implicitly carries a response to near-surface phenomena. A major limitation here has been that wind stress measurements are not available on anywhere near the scale

Corresponding author address: Douglas Vandemark, NASA/ GSFC, Bldg. N-159, Wallops Island, VA 23337.

E-mail: vandemark@gsfc.nasa.gov of buoy and ship wind speed data. Field data have just recently become available (Colton et al. 1995; Weismann et al. 1994) that indicate Ku-band scatterometer backscatter is more closely correlated with $\mathrm{u}_{*}$ than with 10-m wind speed.

A clear connection between altimeter radar cross section $\left(\sigma_{0}\right)$ and sea surface wind stress is not yet established. Wu (1992) proposed an altimeter algorithm for wind stress based on the physical relationship of altimeter response to changes in ocean ripples and on examination of the modified Chelton-Wentz (MCW) (Witter and Chelton 1991) altimeter wind speed retrieval algorithm. However, aside from several studies on sea state effects (Glazman and Greysukh 1993; Queffeulou et al. 1995), there is little published data to support or deny measurable nonwind effects on the altimeter-wind speed relationship. This may be because of a scarcity of altimeter measurements collected over well-instrumented research sites. Nonetheless, theory suggests a strong parallel between surface wind stress and altimeter backscatter in that both are formed through partial integration of the wave slope distribution (Brown 1979; Kitaigorodskii 1973). If a satellite altimeter can reliably retrieve wind stress, this may aid refinement of other satellite sensor and general circulation model wind stress estimates.

Recently, aircraft altimeter backscatter data were collected over open-ocean research platforms during the High Resolution Remote Sensing program. Our objec- 


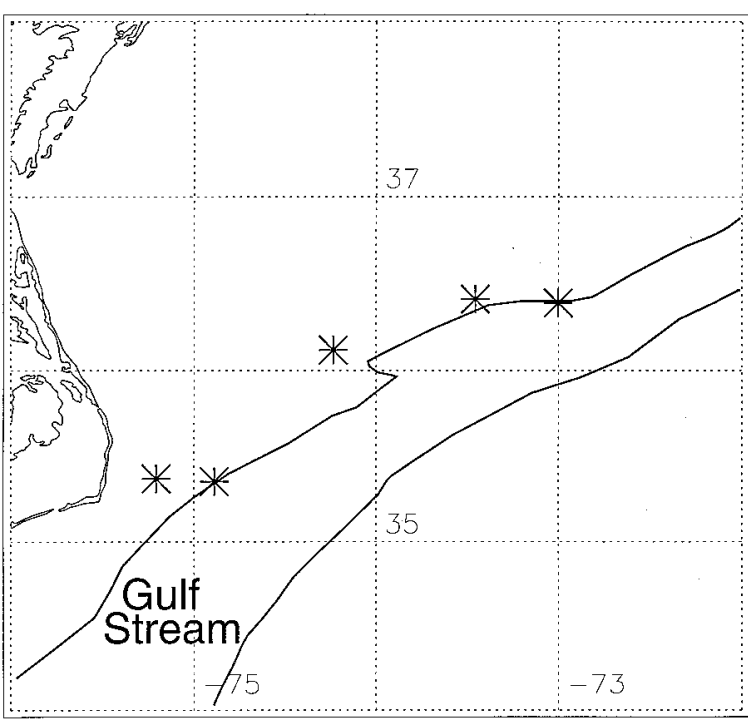

FIG. 1. Map of the High Resolution Program, June 1993 experiment area. The area is centered near $36^{\circ} \mathrm{N}, 74^{\circ} \mathrm{W}$. Gulf Stream is depicted based on AVHRR imagery of 18 June 1993. Symbols represent the vicinity of $\mathrm{R} / \mathrm{V}$ measurements for each of five ROWS flight days.

tive is to use the resulting altimeter-in situ dataset to examine altimeter $\sigma_{0}$ conversion to wind and wind stress relying primarily on the MCW satellite wind speed algorithm.

\section{Remote and in situ measurements}

\section{a. Experiment background}

Data for this presentation were collected during the Office of Naval Research High Resolution Remote Sensing experiment of June 1993. Near-surface environmental measurements were made by the R/V Iselin, the LADAS (laser slope gauge, acoustic Doppler current meter, acoustic anemometer, sodar) platform, and USNS Bartlett. A map of R/V locations for five separate aircraft flight days is provided in Fig. 1. The ships were generally located near the Gulf Stream north wall. Aircraft radar altimeter overflights of the experiment area occurred on 11, 14, 17, 20, and 27 June. NASA's T-39 aircraft carried the Radar Ocean Wave Spectrometer (ROWS), with its $\mathrm{Ku}$-band radar altimeter, at a nominal altitude of $5500 \mathrm{~m}$. Typically the aircraft was over the experiment area for a period lasting between 1.5 and 2 $\mathrm{h}$ during each flight, passing near the ships intermittently.

\section{b. Surface measurements}

Extensive near-surface measurements were acquired by the research vessels. These included wind and wind stress vectors, as well as parameters needed to determine atmospheric stratification. Wind speeds were measured at heights ranging from 6 to $12 \mathrm{~m}$ and adjusted to 10 $m$ using the boundary layer model of Fairall et al. (1996). Friction velocity estimates were made using inertial dissipation (Iselin, LADAS, Bartlett) and direct eddy correlation (Iselin, LADAS) methods. We note that the inertial dissipation technique does not provide wind stress vector direction. Near-surface currents were estimated based on current measurements made at $1 \mathrm{~m}$ (LADAS) to several meters depth (ship-based ADCP). Because the ships were often in the Gulf Stream, nearsurface current vector measurements were crucial for correct boundary layer characterization. Wind speeds relative to the earth (the absolute wind speed) and relative to the drift current were computed. All parameters were derived using a 10-min averaging period. Uncertainty for the 10-min-averaged wind and friction velocity estimates is less than $10 \%$ and $30 \%$, respectively. These somewhat higher than normal uncertainties are mainly due to the nonhomogeneous conditions encountered near the Gulf Stream edge.

Wind conditions for the five ROWS flights varied from a very light wind event to moderate $10 \mathrm{~m} \mathrm{~s}^{-1}$ southerly flow. Significant wave height was $1.5 \mathrm{~m}$ on 14 and 27 June, below $1.0 \mathrm{~m}$ otherwise. The range of air-sea temperature difference was $-5.6^{\circ}$ to $3.9^{\circ}$, the range of the stability parameter $z / L$ (at $10 \mathrm{~m}$ ) was -0.5 to 0.82 , and the range of effective current (current with respect to wind vector) was -2.0 to $+0.5 \mathrm{~m} \mathrm{~s}^{-1}$.

\section{c. Aircraft altimeter measurements}

The airborne altimeter measurements were made using NASA's airborne ROWS. This Ku-band (2.24-cm wavelength) radar system comprises both an altimeter and a scanning high-resolution scatterometer (Vandemark et al. 1994a). ROWS altimeter data are collected using a pulse-limited altimeter technique associated with wide-beam horn antenna operation. The altimeter derives cross section rolloff versus incidence angle from the omnidirectional return signal (Hammond et al. 1977). Incidence angle coverage is near vertical, from $0^{\circ}$ out to $12^{\circ}$. Slope of the falloff is proportional to rms sea surface slope and after correction for the antenna pattern is termed the $\mathrm{Ku}$-band mean-square slope $\left(\mathrm{mss}_{\mathrm{ku}}\right)$. The subscript differentiates altimeter mss from the true or total surface slope because diffraction effects limit the microwave sensor to a partial integration of total slope. The altimeter signal reflects off a "filtered surface" composed of all length scales greater than about three times the transmit wavelength. Theoretical prediction and measurements show that mean-square slope is inversely proportional to altimeter $\sigma_{0}$ at $0^{\circ}$ incidence (the pulse-limited altimeter $\sigma_{0}$ ) (Brown 1978; Hammond et al. 1977; Jackson et al. 1992). For a Ku-band altimeter,

$$
\sigma_{0}\left(\theta=0^{\circ}\right)=\frac{R_{\mathrm{eff}}}{\mathrm{mss}_{\mathrm{ku}}},
$$

where we define $R_{\text {eff }}$ as an effective Fresnel coefficient 
and $\theta$ as the radar's pointing or incidence angle. We convert the ROWS $\mathrm{mss}_{\mathrm{ku}}$ to Ku-band $\sigma_{0}\left(0^{\circ}\right)$ using $R_{\text {eff }}$ $=0.34$. This number compares well with others at Ku-band (Wu 1992; Apel 1994; Jackson et al. 1992). Compilation and processing details for this dataset are given in Vandemark et al. (1994b). ROWS mss $_{\mathrm{ku}}$ estimates are generated at $2-\mathrm{km}$ intervals along the flight track and the nominal area for each estimate is $2 \mathrm{~km}^{2}$. Uncertainty of the $\mathrm{mss}_{\mathrm{ku}}$ measurement is estimated at 5\% due to antenna pattern measurement and processing algorithm limitations. This translates to about $0.2 \mathrm{~dB}$ in $\sigma_{0}$.

\section{d. Altimeter wind speed and friction velocity algorithms}

The modified Chelton-Wentz wind speed retrieval algorithm is used to convert our altimeter $\sigma_{0}$ to altimeterderived wind speed at $10 \mathrm{~m}\left(U_{10 \mathrm{MCW}}\right)$. MCW is given in tabular format without a closed functional dependence between wind and $\sigma_{0}$. This model was empirically derived for the Ku-band satellite altimeter. Independent buoy comparisons indicate a root-mean-square algorithm-buoy wind speed difference of $1.9 \mathrm{~m} \mathrm{~s}^{-1}$, a result recently affirmed by Gower (1996) using TOPEX satellite altimeter data. The intercomparison error budget comprises the algorithm, buoy uncertainties, sensor noise, and time-space sampling differences (Monaldo 1988).

Wu (1992) proposed an altimeter friction velocity algorithm that simply combined his semianalytical altimeter wind speed algorithm with a wind stress, or drag, coefficient. The open-ocean, neutral stability drag coefficient at $10 \mathrm{~m}\left(\mathrm{Cd}_{10}\right)$ was defined as

$$
\begin{aligned}
\mathrm{Cd}_{10}= & {\left[\left(\frac{1}{\kappa}\right) \ln \left(\mathrm{Cd}_{10}^{1 / 2} U_{10} \frac{10}{\nu}\right)+5.5\right]^{-2}, } \\
& U_{10}<2.4 \mathrm{~m} \mathrm{~s}^{-1} \\
\mathrm{Cd}_{10}= & \left(0.8+0.065 U_{10}\right) 10^{-3}, \\
& U_{10}>2.4 \mathrm{~m} \mathrm{~s}^{-1},
\end{aligned}
$$

where $\nu$ is the kinematic viscosity of air and $\kappa=0.4$ is the von Kármán constant. Our proposed altimeter $u_{*}$ algorithm is also a mapping of altimeter $\sigma_{0}$ into friction velocity using (2), but for altimeter wind speed we use the empirically derived MCW algorithm to give

$$
u_{* \mathrm{MCW}}=\mathrm{Cd}_{10}^{1 / 2} U_{10 \mathrm{MCw}} \text {. }
$$

Note that both terms on the right-hand side of (3) are assumed to represent open-ocean, neutral stratification conditions.

Equations (2) and (3) imply that surface wind stress and wind speed are, on average, closely coupled. However, it is recognized that significant deviation from this average relationship can occur with surface layer stratification changes and because wind stress is also affected by additional near-surface, nonwind phenomena such as drift current and shear, slicks, swell, and wave steepness (Geernaert and Plant 1990). If altimeter $\sigma_{0}$ and $u_{*}$ are indeed more highly correlated than $\sigma_{0}$ and $U_{10}$, Eq. (3) will provide a better alternative for single parameter inversion between the Ku-band altimeter and a measurable geophysical parameter.

\section{Results}

\section{a. Wind speed}

After assembling R/V and aircraft datasets, coincident pairs were found using a search radius of $\pm 30 \mathrm{~min}$ and $\pm 15 \mathrm{~km}$. The resulting dataset contains 39 samples. Sampling is spatial for the altimeter with a footprint equal to $2 \mathrm{~km}^{2}$, and temporal for the R/V data with an averaging time equal to $10 \mathrm{~min}$. These are of the same order, as $10 \mathrm{~min}$ at nominal $7 \mathrm{~m} \mathrm{~s}^{-1}$ wind advection would amount to a sampling of $4 \mathrm{~km}$ along wind. This sampling is at a slightly higher resolution than typical satellite altimeter-buoy comparisons that use about 6-km along-track altimeter data $\left(\sim 12 \mathrm{~km}^{2}\right)$ and 10 -min buoy averages.

Figure 2 shows wind speed estimates at $10 \mathrm{~m}$ versus altimeter $\sigma_{0}$. Abscissas for the three plots are, respectively, wind speed with respect to earth reference (absolute wind speed), with respect to surface current (relative wind speed), and with both current and atmospheric stability adjustments applied. The range of wind speeds is $2-12 \mathrm{~m} \mathrm{~s}^{-1}$. The MCW wind speed algorithm is shown on all plots. Altimeter cross-section values appear above the curve (negative wind speed bias) at light winds, but there is good overall agreement between data and model. Improved agreement between data and MCW model is apparent for successive wind corrections at both light and higher wind speeds. Statistics from the direct comparison of altimeter- and in situ-derived wind speed are given in Table 1. Marked improvement in each statistical parameter is found as wind corrections are applied. The largest improvements appear to come with the adjustment for current.

For these data, MCW-derived altimeter wind speed is most closely related to an adjusted wind speed, not the true wind speed. The $11 \%$ increase in regression correlation coefficient $R$ is considerable. Bias and rms uncertainty are lowered by a factor nearing 2 . Thus, the altimeter wind speed inversion is subject to nonwind effects. Moreover, best agreement with adjusted wind speed suggests the link between friction velocity and altimeter $\sigma_{0}$.

\section{b. Friction velocity}

Friction velocity versus altimeter $\sigma_{0}$ is shown in the upper panel of Fig. 3. The model is altimeter $u_{*}$ MCw (3). Data agree closely with the model although $\sigma_{0}$ values are slightly high at lighter winds. Direct comparison 

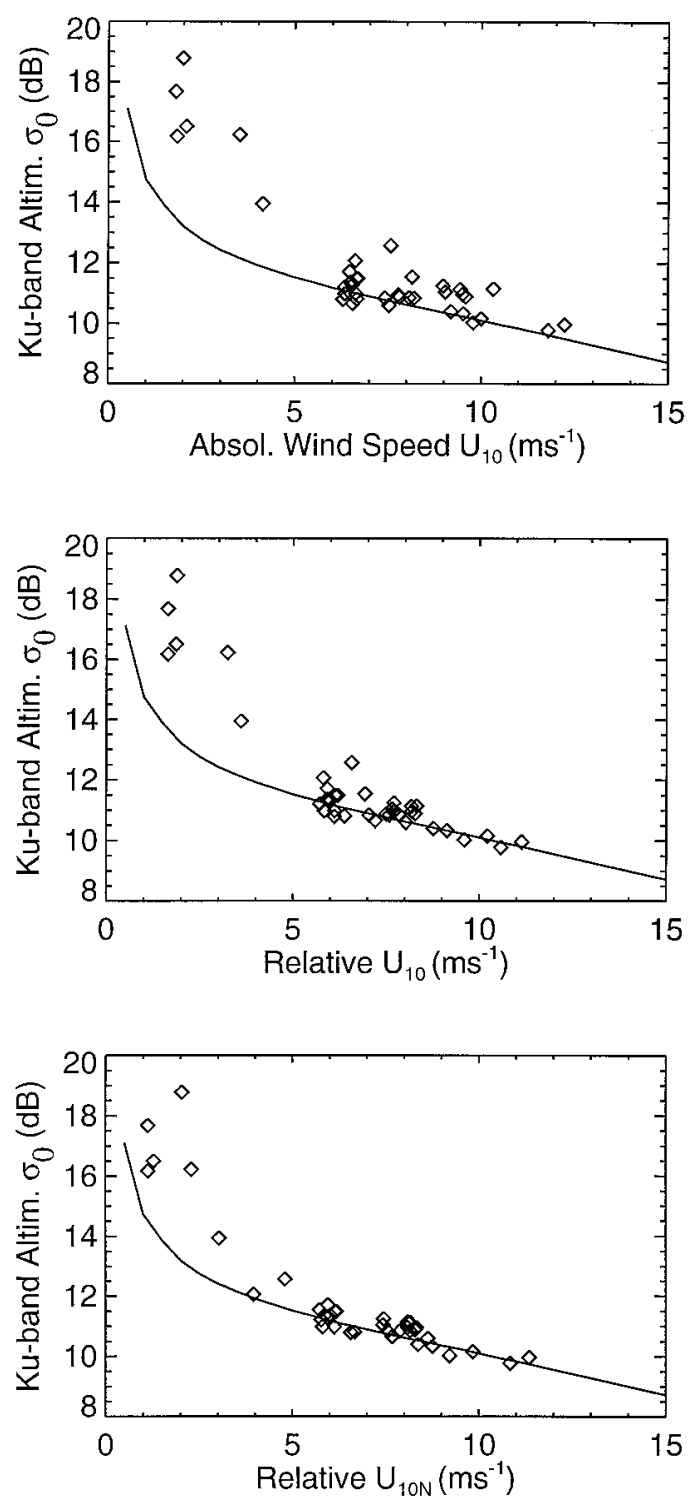

FIG. 2. Ku-band altimeter normalized radar cross section (NRCS) and R/V absolute and adjusted wind speed measurements. The curve is the MCW 10-m wind speed algorithm. Adjustment of R/V 10-m wind speed estimates between plots is indicated.

TABLE 1. Correlation coefficient, bias, and root-mean-square error between in situ and altimeter wind and friction velocities.

\begin{tabular}{lccc}
\hline \hline \multicolumn{1}{c}{ Wind comparisons } & $R$ & Bias $\left(\mathrm{m} \mathrm{s}^{-1}\right)$ & rms error \\
\hline$U_{10}$ vs $U_{10}$ MCw & 0.86 & -1.41 & 1.43 \\
Relative $U_{10}$ vs $U_{10 \mathrm{MCw}}$ & 0.93 & -0.83 & 1.10 \\
Relative $U_{10 \mathrm{~N}}$ vs $U_{10 \mathrm{MCw}}$ & 0.96 & -0.69 & 0.86 \\
Bulk $u_{*} \mathrm{vs} u_{* \mathrm{MCW}}$ & 0.94 & -0.029 & 0.037 \\
$u_{*}$ vs $u_{*} \mathrm{MCw}$ & 0.93 & -0.016 & 0.039 \\
\hline
\end{tabular}
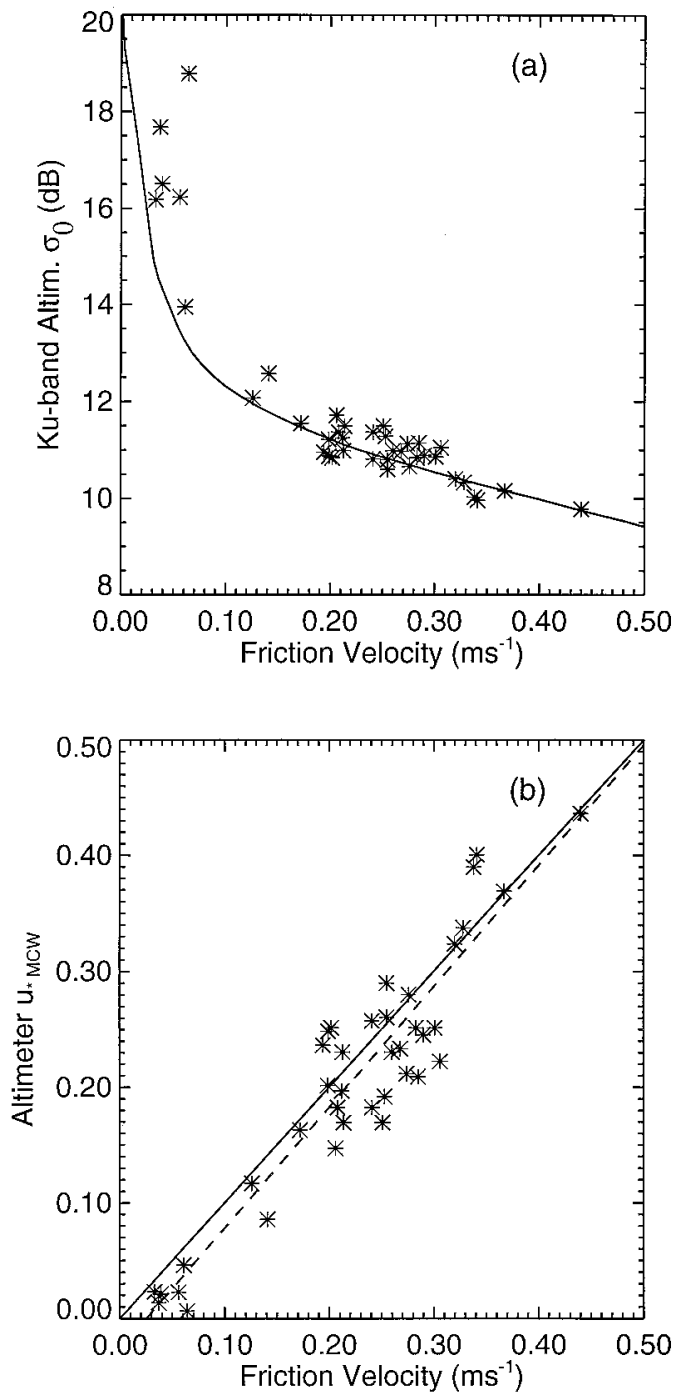

FIG. 3. (a) Ku-band altimeter $\sigma_{0}$ and $\mathrm{R} / \mathrm{V}$ friction velocity measurements. The curve is the proposed $u_{* \text { MCw }}$ algorithm. (b) Scatterplot of altimeter- and $\mathrm{R} / \mathrm{V}$-derived friction velocities. Linear regression (dashed) is shown.

between altimeter- and ship-derived $u_{*}$ is shown in the bottom panel. A linear fit gives a slope of 1.04 and intercept of -0.026 . Statistics are again shown in Table 1 . We include comparison to $u_{*}$ derived using the bulk method. In large part, bulk-derived friction velocity and adjusted $10-\mathrm{m}$ wind speeds are the same entity. Therefore, we have included this entry to allow further comparison between the adjusted wind speed and turbulence-derived estimates of $u_{*}$ found from the inertialdissipation and direct covariance methods. The comparison bias using turbulence-derived estimates is half that when using the bulk data, otherwise the two $u_{*}$ comparisons are very similar. Table 1 then indicates that altimeter-derived wind stress is as viable a derivative as corrected wind speed and clearly an improvement over an inversion to true wind speed. 


\section{c. Current and atmospheric stability effects on $u_{*-}$ altimeter correlation}

The altimeter and in situ friction velocity comparison demonstrates very good agreement between our measurements and model. Remaining scatter between those measurements is presented here to examine the robustness of this direct mapping between altimeter $\sigma_{0}$ and $u_{*}$.

Previously, Wu (1991) found that both optical meansquare slope (in situ) and C-band scatterometer (remote) data indicated enhanced (suppressed) small-scale surface roughness under unstable (stable) atmospheric conditions at a given wind speed. This indicated a closer tie between those measurements and surface wind stress than between those measurements and wind speed. However, Wu went on to find that both sensors measured a response to stratification change that was stronger than the response of wind stress to the same conditions. The conclusion was that a significant air-sea temperature dependence still existed to preclude direct mapping between $u_{*}$ and those particular measurements. The altimeter differs significantly from those sensors in its response to surface roughness, and we now examine our measurements in the presence of current and stability influences to see how altimeter and $u_{*}$ measurements behave.

The difference between altimeter and in situ $u_{*}$ estimates is presented here as a ratio between the actual altimeter mean-square slope measurements and the prediction from our proposed $u_{*}$-altimeter model (3). This approach provides consistency with past studies (Hwang and Schemdin 1988; $\mathrm{Wu}$ 1991). Recall that $\mathrm{mss}_{\mathrm{ku}}$ is directly tied to altimeter $\sigma_{0}$ through (1). Inversion of (3) using in situ friction velocity input provides the normalizing mss $_{u_{*}}$ :

$$
S_{r}=\frac{\mathrm{mss}_{\mathrm{ku}}}{\mathrm{mss}_{u *}}
$$

The upper plot of Fig. 4 shows this altimeter meansquare slope ratio $S_{r}$ against effective current for each sample. Ambient or effective current $v$ is defined here as the current vector's dot product with the unit wind vector. For almost all of these samples, wind and current directions were at least partially aligned, giving an effective wind suppression or negative current. There is a significant spread in $S_{r}$ with current, but also an apparent positive correlation. An effective current stronger than $-1.0 \mathrm{~m} \mathrm{~s}^{-1}$ suppresses $\mathrm{mss}_{\mathrm{ku}}$ in comparison to the still-water $u_{*}$ relationship. The plus symbols in both panels of Fig. 4 represent data collected in very stable atmospheric conditions. If these outliers $(10 / L>0.2)$ are excluded from the data, a linear regression yields

$$
S_{r}=1.02+0.05 v \pm 0.063 .
$$

The bottom plot of Fig. 4 shows $S_{r}$ against the dimensionless Monin-Obukhov stability length, $L$, at $10 \mathrm{~m}$. In stable conditions, $\mathrm{mss}_{\mathrm{ku}}$ is reduced relative to $u_{*}$ for
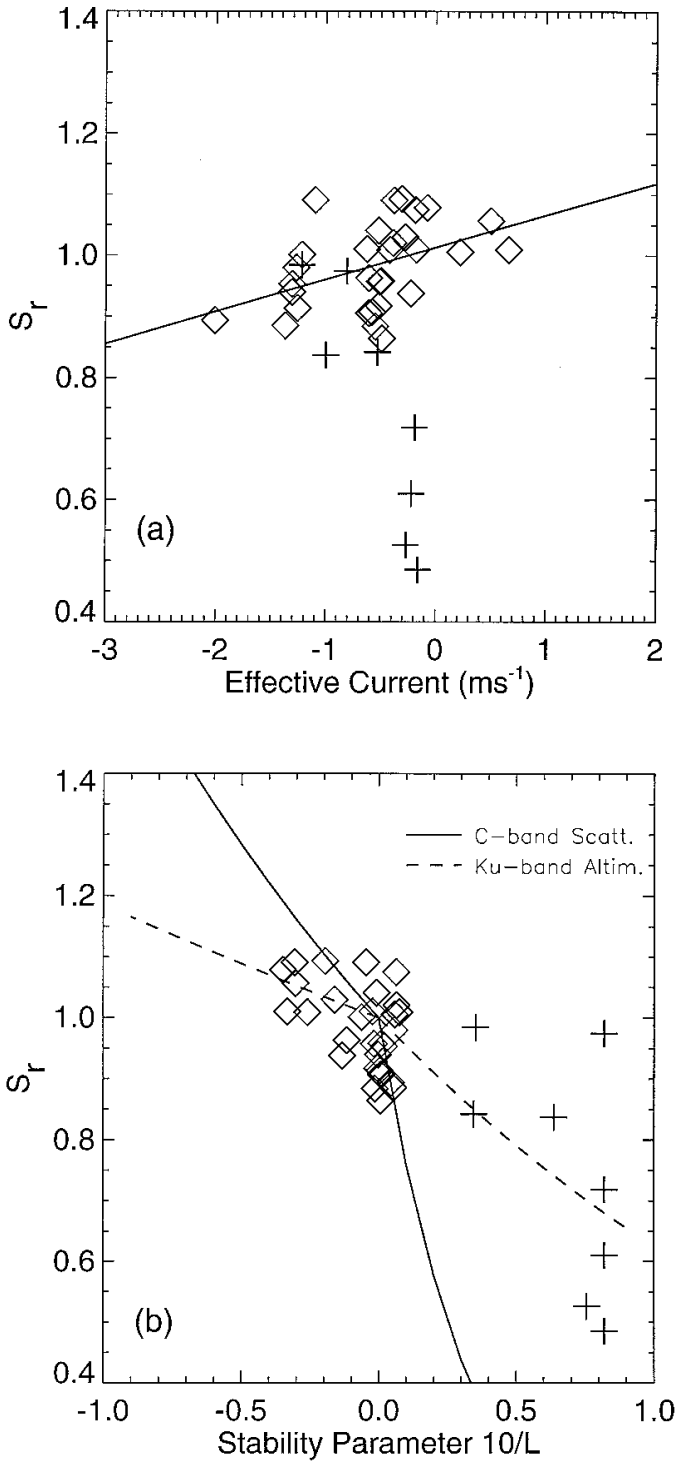

FIG. 4. Environmental parameters (a) effective current, and (b) stability vs altimeter measurement deviation, Eq. (5), from the $u_{* \text { MCW }}$ algorithm. Measurements in stable stratification are denoted with the "+" symbol. In (a) a linear regression for $S_{r}$ vs current is shown. In (b), solid curve is (6) and (7) with exponents from the C-band scatterometer. Dashed curve is the present data fit to (6) and (7) giving $\alpha=0.17$ and $\beta=0.47$.

several samples but not all. In unstable conditions, the departure from $u_{*}$ is not strong. Model curves on the plot are based on previous empirical examination of atmospheric stability and small-scale wave observations (Wu 1991). The form proposed was

unstable cases

$$
S_{r}=e^{(-\alpha 10 / L)},
$$

stable cases

$$
S_{r}=e^{(-\beta 10 / L)} .
$$


The Ku-band mss data do not support the large coefficients ( $\alpha=16.5, \beta=3.1$ ) suggested by Wu for optical mean-square slope data of Hwang and Schemdin (1988). These values predict very strong slope growth (suppression) with instability (stability). As notably, they suggest a large departure between optically derived slope and wind stress response. The solid curve in Fig. $4 \mathrm{~b}$ is that suggested for C-band (Keller et al. 1989), $45^{\circ}$ incidence, scatterometer $\sigma_{0}$ ratio data; having a much smaller value in unstable conditions $(\alpha=0.50, \beta=$ $2.75)$. These values also appear too drastic for the present $S_{r}$ data. Best fit for the Ku-band altimeter data is $\alpha$ $=0.17$ and $\beta=0.47$ (dashed curve) with large scatter that clearly limits our confidence in these values. However, the data do indicate less departure than for the optical and scatterometer results.

The considerable scatter found in Fig. 4 points to the limited size and constraints of our dataset. Further data are needed to confirm or deny the slightly differing responses of altimeter $\mathrm{mss}_{\mathrm{ku}}$ and direct covariance $u_{*}$ measurements to these nonwind parameters. The main point is that there is not a big divergence between them; nominally less than $15 \%$ for a broad range of both surface current and stability conditions.

For atmospheric stability, these data appear to support the idea of enhancement (suppression) with atmospheric instability (stability) beyond that of friction velocity's response, but altimeter-derived $u_{*}$ has much closer agreement with in situ $u_{*}$ than was found for scatterometer or optical slope measurements. We note that one primary difference between sensors is that the microwave altimeter is somewhat "blind" to very short-scale gravity capillary waves (Brown 1978), while the scatterometer and optical slope sensor are very sensitive to them. Thus, previous results (Wu 1991) may imply this narrow gravity-capillary wave regime (waves less than approximately $6-\mathrm{cm}$ wavelength) is more responsive to stratification effects than are the respective integrated slope domains that are thought to dictate altimeter $\sigma_{0}$ (Brown 1978) and wind stress (Kitaigorodskii 1973).

\section{Concluding remarks}

Results of the $\mathrm{Ku}$-band altimeter-in situ wind speed comparisons indicate that MCW-derived altimeter wind speed is most closely related to an adjusted $10-\mathrm{m}$ wind speed, not the true wind speed. Adjusting wind estimates for surface current and atmospheric stability effects provided clear improvement in the wind data comparison. There was a factor of 2 reduction in bias and of 1.6 in rms error. This result is not fully supported or agreed upon in the literature. For example, when developing a statistical altimeter wind model, Freilich and Challenor (1995) assumed a monotonic relationship between wind speed and $\sigma_{0}$ and also assumed near-surface influences are negligibly small. The present dataset was of limited size, but collected over a region with strong current and for a fairly broad range of stratification. These local nonwind influences will be present in a global sampling, and our data suggest they will be an error source in satellite altimeter wind speed retrieval.

Perhaps the more fundamental finding is derived from the altimeter-in situ friction velocity comparisons. These measurements indicate that $\mathrm{Ku}$-band altimeter $\sigma_{0}$ is more highly correlated with $u_{*}$ than with the $10-\mathrm{m}$ wind speed. A single parameter (current, stratification, or other ancillary data not required) mapping between altimeter $\sigma_{0}$ and $u_{*}$ shows very good agreement for $u_{*}$ ranging from 0.0 to $0.4 \mathrm{~m} \mathrm{~s}^{-1}$. A drag coefficient from $\mathrm{Wu}$ (1992) and the MCW wind speed algorithm were used for our altimeter- $u_{*}$ algorithm (3), but we find that the general characteristics of Table 1 hold for other lightto-moderate wind altimeter routines (e.g., Brown et al. 1981) and drag coefficients (e.g., Smith 1988). In summary, these field data suggest that Ku-band altimeter backscatter data would be better used for direct wind stress derivation rather than for wind speed.

Acknowledgments. We thank J. Hare, A. Karachintsev, and G. Young for their help in collecting the Iselin data, and T. Donato, J. Kaiser, G. Mormorino, and C. Trump for their help in collecting the Bartlett data. We also thank D. Hines and K. Stewart for their work with ROWS. This work was supported by NASA's Physical Oceanography Program Grant 461-31-05 and the Office of Naval Research Grants N00014-92-J-1585 and N00014-94-MP-23031.

\section{REFERENCES}

Apel, J. R., 1994: An improved model of the ocean surface wave vector spectrum and its effects on radar backscatter. J. Geophys. Res., 99, 16 269-16291.

Brown, G. S., 1978: Backscattering from a Gaussian-distributed perfectly conducting rough surface. IEEE Trans. Antennas Propag., 26, 472-482.

_ 1979 : Estimation of surface wind speeds using satellite-borne radar measurements at normal incidence. J. Geophys. Res., 84, 3974-3978.

- H. R. Stanley, and N. A. Roy, 1981: The windspeed measurement capability of spaceborne radar altimetry. IEEE J. Oceanic Eng., OE-6, 59-63.

Colton, M., W. J. Plant, W. C. Keller, and G. L. Geernaert, 1995: Tower-based measurements of normalized radar cross section from Lake Ontario: Evidence of wind stress dependence. J. Geophys. Res., 100, 8791-8813.

Fairall, C. W., E. F. Bradley, D. P. Rogers, J. B. Edson, and G. S. Young, 1996: Bulk parameterization of air-sea fluxes for Tropical Ocean-Global Atmosphere Coupled-Ocean Atmosphere Response Experiment. J. Geophys. Res., 101, 3747-3764.

Freilich, M. H., and P. G. Challenor, 1995: A new approach for determining fully empirical altimeter wind speed model functions. J. Geophys. Res., 99, 25 051-25062.

Geernaert, G. L., and W. J. Plant, Eds., 1990: Surface Waves and Fluxes. Vol. I, Current Theory. Kluwer Academic, 336 pp.

Glazman, R. E., and A. Greysukh, 1993: Satellite altimeter measurements of surface wind. J. Geophys. Res., 98, 2475-2483.

Gower, J. F. R., 1996: Intercalibration of wave and wind data from TOPEX/POSEIDON. J. Geophys. Res., 101, 3817-3829.

Hammond, D. L., R. A. Menella, and E. J. Walsh, 1977: Short pulse 
radar used to measure sea surface wind speed and SWH. IEEE J. Oceanic Eng., OE-2, 61-67.

Hwang, P. A., and O. H. Schemdin, 1988: The dependence of sea surface slope on atmospheric stability and swell conditions. $J$. Geophys. Res., 93, 13 903-13 912.

Jackson, F. C., W. T. Walton, B. A. Walter, and C. Y. Peng, 1992: Sea surface mean square slope from Ku-band backscatter data. J. Geophys. Res., 97, 11 411-11 427.

Keller, W. C., V. Wismann, and W. Alpers, 1989: Tower-based measurements of the ocean $\mathrm{C}$ band radar backscattering cross section. J. Geophys. Res., 94, 924-930.

Kitaigorodskii, S. A., 1973: The Physics of Air-Sea Interactions. Keter Press, 237 pp.

Monaldo, F., 1988: Expected differences between buoy and radar altimeter estimates of wind speed and significant wave height and their implications on buoy-altimeter comparisons. J. Geophys. Res., 93, 2285-2302.

Queffeulou, P., T. Elfouhaily, V. Kerbaol, P. Le Borgne, and J. M. Lefevre, 1996: Remote sensing of wind and waves over the western Mediterranean Sea. Proc. Second ERS Pilot Project Workshop, London, United Kingdom, European Space Agency, 47-52.

Smith, S. D., 1988: Coefficients for sea surface wind stress. J. Geophys. Res., 93, 15 467-15 472.

Stoffelen, A., and D. L. T. Anderson, 1993: ERS-1 scatterometer data characteristics and wind retrieval skill. Proc. First ERS-1 Symp. Cannes, France, European Space Agency, 41-47.

Vandemark, D., F. C. Jackson, E. J. Walsh, and B. Chapron, 1994a: Airborne radar measurements of ocean wave spectra and wind speed during the Grand Banks ERS-1 SAR Wave Experiment. Atmos.-Ocean, 32, 143-178.

- D. Hines, S. Bailey, and K. Stewart, 1994b: Airborne ROWS data report for the High Resolution Experiment, June 1993. NASA Tech. Memo. NASA/TM-104609, 73 pp. [Available from NASA/Goddard Space Flight Center, Greenbelt, MD 20771.]

Weismann, D. E., K. L. Davidson, R. A. Brown, C. A. Friehe, and F. Li, 1994: The relationship between the microwave radar cross section and both wind speed and stress: Model function studies using Frontal Air-Sea Interaction Experiment data. J. Geophys. Res., 99, $10087-10108$.

Wentz, F. J., 1992: Measurement of oceanic wind vector using satellite microwave radiometers. IEEE Trans. Geosci. Remote Sens., 30, 960-972.

Witter, D. L., and D. B. Chelton, 1991: A Geosat altimeter wind speed algorithm and a method for altimeter wind speed algorithm development. J. Geophys. Res., 96, 8853-8860.

Wu, J., 1991: Effects of atmospheric stability on ocean ripples: A comparison between optical and microwave measurements. $J$. Geophys. Res., 96, 7265-7269.

_ 1992 : Near-nadir microwave specular returns from the sea surface-Altimeter algorithms for wind and wind stress. J. Atmos. Oceanic Technol., 9, 659-667. 